\title{
Wildly Growing Asparagus (Asparagus officinalis L.) Hosts Pathogenic Fusarium Species and Accumulates Their Mycotoxins
}

\author{
Lukasz Stẹpień $^{1}$ • Agnieszka Waśkiewicz ${ }^{2}$. Monika Urbaniak ${ }^{1}$
}

Received: 23 October 2015 / Accepted: 3 December 2015 /Published online: 21 December 2015

(C) The Author(s) 2015. This article is published with open access at Springerlink.com

\begin{abstract}
Asparagus officinalis L. is an important crop in many European countries, likely infected by a number of Fusarium species. Most of them produce mycotoxins in plant tissues, thus affecting the physiology of the host plant. However, there is lack of information on Fusarium communities in wild asparagus, where they would definitely have considerable environmental significance. Therefore, the main scientific aim of this study was to identify the Fusarium species and quantify their typical mycotoxins present in wild asparagus plants collected at four time points of the season. Forty-four Fusarium strains of eight species-Fusarium acuminatum, Fusarium avenaceum, Fusarium culmorum, Fusarium equiseti, Fusarium oxysporum, Fusarium proliferatum, Fusarium sporotrichioides, and Fusarium tricinctumwere isolated from nine wild asparagus plants in 2013 season. It is the first report of $F$. sporotrichioides isolated from this particular host. Fumonisin $\mathrm{B}_{1}$ was the most abundant mycotoxin, and the highest concentrations of fumonisins $\mathrm{B}_{1}-\mathrm{B}_{3}$ and beauvericin were found in the spears collected in May. Moniliformin and enniatins were quantified at lower concentrations. Mycotoxins synthesized by individual strains obtained from infected asparagus tissues were assessed using in vitro cultures on sterile rice grain. Most of the $F$. sporotrichioides strains
\end{abstract}

Łukasz Stępień

lste@igr.poznan.pl

1 Department of Pathogen Genetics and Plant Resistance, Institute of Plant Genetics, Polish Academy of Sciences, Strzeszyńska 34, 60-479 Poznań, Poland

2 Department of Chemistry, Poznań University of Life Sciences, Wojska Polskiego 75, 60-625 Poznań, Poland synthesized HT-2 toxin and $F$. equiseti strains were found to be effective zearalenone producers.

Keywords Fumonisins $\cdot$ Fungal plant pathogens $\cdot$ Molecular identification · Natural Fusarium populations .

Trichothecenes $\cdot$ Zearalenone

\section{Introduction}

Asparagus officinalis L. is a seasonal crop of high economic importance in the countries of Central and Western Europe [1, 2]. With perennial growth habit, asparagus plants are prone to be infected by fungi, acting rather like endophytes or opportunistic plant pathogens than biotrophic microorganisms. Asparagus has been regarded as one of the most versatile hosts for fungi, likely to be colonized by various Fusarium species [3]. Fusarium oxysporum and Fusarium proliferatum are usually the most commonly occurring species in cultivated plants, although Fusarium avenaceum, Fusarium culmorum, and Fusarium solani have also been identified in naturally infected asparagus spears [4-7]. Furthermore, despite symptomless type of growth often reported for many Fusarium species, many of them are able to produce mycotoxins in plant tissues [8], which influence physiology of the host plant [9]. It has been reported that trichothecenes, zearalenone, and fumonisins are among Fusarium-produced metabolites that are the most harmful when consumed with food and feed by animals and humans [10]. F. proliferatum is one of the most effective fumonisin B producers $[11,12]$ and $F$. culmorum, Fusarium graminearum, and Fusarium cerealis are able to produce large amounts of group B trichothecenes (either deoxynivalenol or nivalenol), and, along with Fusarium equiseti, of zearalenone [13-15]. On the other hand, Fusarium sporotrichioides and Fusarium poae synthesize a 
range of group A trichothecenes [16, 17]. Besides fumonisins and, possibly, trichothecenes, moniliformin and beauvericin appear as the most likely present metabolites in asparagus plants [18]. The fungal presence in the basal part of spears is usually more frequent than in the apical part, suggesting that the fungus can spread inside the plant colonizing particularly heavily the underground plant parts - crowns and roots [18]. Similarly to other perennial crop species colonized by Fusarium species [19-21], the mycotoxin-contaminated asparagus plants, when consumed, pose a serious risk of mycotoxin intake. Therefore, continuously updated knowledge of the physiology and mycotoxicity of fungal community present in perennial crops becomes essential to avoid the risk of the exposure to mycotoxin-contaminated foodstuff. Moreover, fungicide control of the crop plant's infection is often difficult, as the endophyte-acting species cause no disease symptoms and host plant response to fungal infection can be significantly changed, as it was already shown for maize [22]. Although the issue has not yet been studied well for asparagus plants, an assumption has been made that some of the mechanisms can be similar in different host species. The role of the mycotoxins synthesized by the endophytes in host plant tissues appears to be essential and, yet, has not been proven. Consequently, it definitely would be interesting to reveal the fungal communities in wild growing plants compared to the typically present in cultivated asparagus plants [4-7]. To answer all those questions, the base of the present study was founded, in which several wildly growing asparagus plants were monitored for the presence of Fusarium species and accumulation of their respective mycotoxins. Thus, the main scientific aims of the research were (a) to identify the Fusarium species and their typical mycotoxins present in plants collected from a longabandoned asparagus orchard, (b) to compare the fungal communities and mycotoxins quantified in plant tissues collected at four time points of the season (May-October 2013), and, finally, (c) to analyze the amounts of mycotoxins synthesized by individual strains obtained from infected asparagus tissues, using in vitro tests.

\section{Materials and Methods}

\section{Wild Asparagus Spears Collection}

Wildly growing asparagus plants used in this study included nine individuals growing in an abandoned fruit orchard of about $500 \mathrm{~m}^{2}$ (Fig. 1) that has not been cropped for over 20 years and makes up for a large wasteland in Poznań, Central Poland. As the area is not used for any crop production, no agricultural influences are being acting nor crop protection techniques are being used. Thus, the plants can be considered as wild, avoiding any of the agricultural pressures. Spears (one piece per plant) have been collected continuously

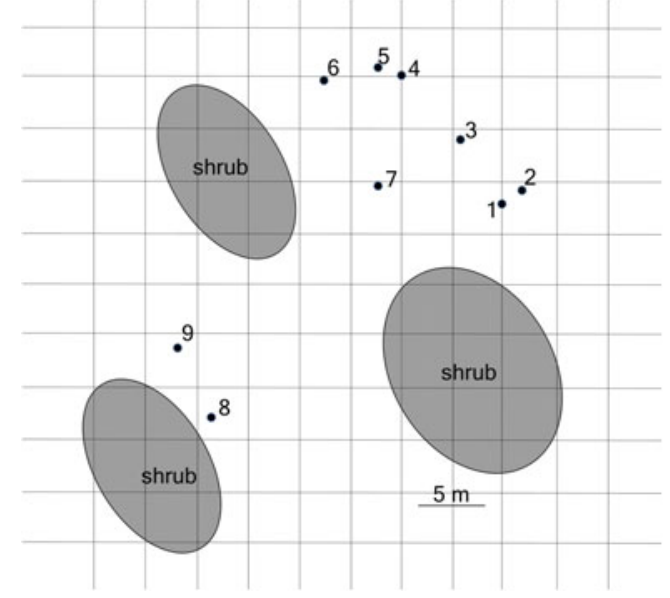

Fig. 1 Schematic map of the area of the growth of nine asparagus plants used in the study

through 2013 season (May-October), i.e., from the start of the vegetation season until the beginning of winter senescence of the plants. Plants were sampled four times: in May, June, July, and October. All of the spears collected did not show visible symptoms of fungal infection, except for some snail damages and partial discoloration and lesions of those gathered in October, likely resulting from lignification process already started. All spears collected were subjected to the isolation of Fusarium fungi and quantification of fumonisins. Where the plant samples were large enough ( $5 \mathrm{~g}$ of fresh weight for each toxin analyzed), the identification and quantification of other mycotoxins have been performed: moniliformin, beauvericin and enniatins, zearalenone, and HT-2 toxin as a representative of the group A trichothecenes. Additionally, mycotoxin contents in the crowns samples of three selected plants were tested as well as in the fruit of only one plant (the remaining plants failed to form fruit in 2013 season).

\section{Fusarium Strains Isolation, Media, and Culture Conditions}

Prior to fungal strain isolation, all plant samples were rinsed with sterile water to remove mineral remnants and surfacesterilized with $70 \%$ ethanol to eliminate microbiological contaminants. Basal parts of the spears were cut into small pieces (three 5-mm slices of each spear) and plated aseptically on the potato dextrose agar (PDA, Oxoid, Basingstoke, UK) medium for 5-7 days at $20-25^{\circ} \mathrm{C}$ and 12 -h photoperiod. Then, growing mycelia of individual Fusarium strains were purified using Leslie and Summerell manual [23] and maintained in pure cultures for 7 days on PDA medium for genomic DNA extraction. All pure strains are maintained at the KF Fusarium Strains Collection at the Institute of Plant Genetics, Polish Academy of Sciences, Poznań, Poland. Number of strains isolated from individual wild asparagus plants has been summarized in Table 1. 
Table 1 Fusarium strains isolated from nine asparagus plants used in the study; the samples were collected at four time points of 2013 season

\begin{tabular}{|c|c|c|c|c|}
\hline \multirow[t]{2}{*}{ Plant no. } & \multicolumn{4}{|l|}{ Date of spears collection } \\
\hline & May 10th & Jun 10th & Jul 15th & Oct 11th \\
\hline$\# 1$ & $\begin{array}{l}\text { F. proliferatum (KF 3792) } \\
\text { F. sporotrichioides (KF 3791) } \\
\text { F. tricinctum (KF 3795) }\end{array}$ & $\begin{array}{l}\text { F. proliferatum (KF 3797) } \\
\text { F. oxysporum (KF 3830) }\end{array}$ & F. proliferatum (KF 3829) & none \\
\hline$\# 2$ & $\begin{array}{l}\text { F. culmorum (KF 3798) } \\
\text { F. equiseti }(\mathrm{KF} 3800) \\
\text { F. proliferatum (KF 3799) }\end{array}$ & $\begin{array}{l}\text { F. tricinctum (KF 3789) } \\
\text { F. equiseti (KF 3832) }\end{array}$ & $\begin{array}{l}\text { F. proliferatum (KF 3801) } \\
\text { F. avenaceum (KF 3803) }\end{array}$ & none \\
\hline$\# 3$ & $\begin{array}{l}\text { F. equiseti (KF 3813) } \\
\text { F. sporotrichioides (KF 3804) }\end{array}$ & F. sporotrichioides (KF 3813) & $\mathrm{n} / \mathrm{a}$ & F. sporotrichioides (KF 3836 \\
\hline$\# 4$ & $\begin{array}{l}\text { F. oxysporum (KF } 3823) \\
\text { F. proliferatum (KF } 3828) \\
\text { F. sporotrichioides (KF 3824) }\end{array}$ & F. sporotrichioides (KF 3825) & $\mathrm{n} / \mathrm{a}$ & F. sporotrichioides (KF 3838) \\
\hline$\# 5$ & $\begin{array}{l}\text { F. acuminatum (KF 3811) } \\
\text { F. proliferatum (KF 3808) } \\
\text { F. sporotrichioides (KF 3812) }\end{array}$ & $\begin{array}{l}\text { F. sporotrichioides (KF 3835) } \\
\text { F. proliferatum (KF } 3810)\end{array}$ & $\mathrm{n} / \mathrm{a}$ & $\begin{array}{l}\text { F. equiseti (KF 3839) } \\
\text { F. sporotrichioides (KF 3840) }\end{array}$ \\
\hline$\# 6$ & F. oxysporum (KF 3790) & F. oxysporum (KF 3805) & F. proliferatum (KF 3806) & $\begin{array}{l}\text { F. oxysporum (KF 3807) } \\
\text { F. proliferatum (KF 4843) } \\
\text { F. proliferatum (KF 3844) }\end{array}$ \\
\hline$\# 7$ & $\mathrm{n} / \mathrm{a}$ & $\begin{array}{l}\text { F. equiseti (KF 3816) } \\
\text { F. oxysporum (KF } 3817) \\
\text { F. sporotrichioides (KF 3818) }\end{array}$ & $\mathrm{n} / \mathrm{a}$ & $\begin{array}{l}\text { F. proliferatum (KF } 3846) \\
\text { F. sporotrichioides (KF } 3847)\end{array}$ \\
\hline$\# 8$ & F. proliferatum (KF 3820) & $\mathrm{n} / \mathrm{a}$ & $\mathrm{n} / \mathrm{a}$ & F. proliferatum (KF 3848) \\
\hline$\# 9$ & $\mathrm{n} / \mathrm{a}$ & F. proliferatum (KF 3822) & F. proliferatum (KF 3827) & none \\
\hline Total & 16 & 13 & 5 & $\begin{array}{l}10 \\
44\end{array}$ \\
\hline
\end{tabular}

n/a no new spears available

\section{DNA Extraction and Molecular Species Identification}

Forty-four Fusarium strains isolated and purified from wild asparagus plants were identified to the species level using molecular techniques following the procedure validated earlier [24] and outlined below. Mycelia of individual strains were harvested from the PDA plates after 7 days of incubation. Genomic DNA was extracted using a hexadecyltrimethylammonium bromide (CTAB) method described previously [25], and the DNA extracts were stored at $-20{ }^{\circ} \mathrm{C}$. Species identification was done on the basis of the sequence analysis of a variable fragment of the translation elongation factor $1 \alpha$ (tef- $1 \alpha)$. Fragments of all strains were PCR-amplified using the following primer pair: for Ef728M, 5' CATCGAGAAGTTCGAGAAGG-3', and for Tef1R, 5'GCCATCCTTGGAGATACCAGC-3'. The primers were successfully validated on wide range of Fusarium species during previous studies $[14,26]$. PCRs were done in $20-\mu \mathrm{L}$ aliquots using $\mathrm{C}-1000$ thermal cyclers (BioRad, Hercules, CA, USA). Each reaction tube contained $0.4 \mu \mathrm{L}$ of Phire II HotStart Taq DNA polymerase (Thermo Scientific, Espoo, Finland), $4 \mu \mathrm{L}$ of $5 \times$ PCR buffer, $12.5 \mathrm{pmol}$ of forward/reverse primers, $2.5 \mathrm{mM}$ of each dNTP, and about $20 \mathrm{ng}$ of fungal DNA. PCR conditions were as follows: $30 \mathrm{~s}$ at $98{ }^{\circ} \mathrm{C} ; 35$ cycles of $5 \mathrm{~s}$ at $98{ }^{\circ} \mathrm{C}, 5 \mathrm{~s}$ at $63{ }^{\circ} \mathrm{C}$, and $15 \mathrm{~s}$ at $72{ }^{\circ} \mathrm{C}$; and $1 \mathrm{~min}$ at $72{ }^{\circ} \mathrm{C}$. Amplicons were electrophoresed in $1.5 \%$ agarose gels (Invitrogen) with Midori Green dye (Nippon Genetics Europe Gmbh).

For sequence analysis, PCR-amplified DNA fragments were purified with exonuclease I (Thermo Scientific) and shrimp alkaline phosphatase (Thermo Scientific) using the following programme: $30 \mathrm{~min}$ at $37^{\circ} \mathrm{C}$ and $15 \mathrm{~min}$ at $80^{\circ} \mathrm{C}$. Both strands were labeled using EF-728 M and Tef1R primers and the BigDyeTerminator 3.1 kit (Applied Biosystems, Foster City, CA, USA), according to Stepień et al. [14] and precipitated with $96 \%$ ethanol. Sequence reading was performed using Applied Biosystems equipment. Sequences of PCR fragments were aligned using BLASTn algorithm to the sequences of reference strains belonging to individual Fusarium species, deposited in the GenBank Database. They were assigned to the reference species, of which both sequence coverages and nucleotide identities were matching the query with $99-100 \%$. All sequences obtained for 44 individual strains of eight Fusarium species isolated from wild asparagus plants have been deposited in the GenBank (NCBI) Database under Accession Numbers: KP729059-KP729102. 


\section{Mycotoxins Analyzed in Asparagus Spears and Fungal Strain Cultures}

Extraction, purification, and HPLC analysis for each mycotoxin in samples of wild asparagus plants and culture samples were done according to detailed procedures described earlier by Stępień and Waśkiewicz [15, 21, 26, 27]. For the quantification of mycotoxin synthesized, each strain was inoculated onto a flask containing $50 \mathrm{~g}$ of sterilized long-grain rice and $12.5 \mathrm{~mL}$ of water, following a procedure described by Stępień et al. [24].

The chromatographic system used to determinate mycotoxins level consisted of Waters 2695 high-performance liquid chromatography (HPLC) unit (Waters, Milford, USA) coupled with Waters 2996 Photodiode Array Detector and Waters 2475 Multi $\lambda$ Fluorescence Detector. EmpowerTM 1 software was used for data processing (Waters, Milford, USA).

Standards of mycotoxins (fumonisins $\mathrm{FB}_{1-3}$, enniatins $\mathrm{A}$, $\mathrm{A}_{1}, \mathrm{~B}, \mathrm{~B}_{1}$, beauvericin, moniliformin, zearalenone, and HT-2 toxin) were purchased with a standard grade certificate from Sigma-Aldrich (Steinheim, Germany). The standard solutions of each mycotoxin (in $\mathrm{ng} / \mu \mathrm{L}$ ) were prepared in methanol. Organic solvents (HPLC grade) and all the other chemicals were also purchased from Sigma-Aldrich (Steinheim, Germany). Water for the HPLC mobile phase was purified using a Milli-Q system (Millipore, Bedford, MA, USA).

Detection limits for individual mycotoxins were as follows: $15 \mathrm{ng} / \mathrm{g}$ for beauvericin, $10 \mathrm{ng} / \mathrm{g}$ for enniatin $\mathrm{A}$ and $\mathrm{A}_{1}, 8 \mathrm{ng} / \mathrm{g}$ for enniatin $B$ and $B_{1}, 3 \mathrm{ng} / \mathrm{g}$ for zearalenone and HT-2 toxin, and $10 \mathrm{ng} / \mathrm{g}$ for moniliformin, and fumonisins $\mathrm{FB}_{1}, \mathrm{FB}_{2}$, and $\mathrm{FB}_{3}[15,21,27,28]$. Because the amounts of FBs in spear samples are usually too low to be detected, fumonisins were concentrated using vacuum evaporation of the extracts and redissolving them in methanol. Thus, the results presented in Table 3 may appear to be lower than the detection limit, because they were calculated for fresh weight amounts.

\section{Results}

\section{Fusarium Species Isolated from Wild Asparagus Plants}

Fusarium community found in nine wild asparagus plants during 2013 season was assessed. The number of Fusarium species in individual asparagus plants observed through four time points has been summarized in Table 1.

Forty-four Fusarium strains were isolated, purified, and characterized, originating from nine asparagus plants from which spears were collected through one whole vegetation season 2013. Eight Fusarium species: Fusarium acuminatum, $F$. avenaceum, $F$. culmorum, $F$. equiseti, $F$. oxysporum, $F$. proliferatum, F. sporotrichioides, and Fusarium tricinctum were identified using molecular analyses based on sequence analysis of $t e f-1 \alpha$ gene. Overall frequencies of the species isolated from all plants from the orchard across the vegetation season are shown on Fig. 2. F. proliferatum and F. sporotrichioides were the prevailing species, and this is the first report of the latter species to be isolated from this host plant. Consistently, the same Fusarium species were frequently isolated from different spears of the same plants, however, it was also demonstrated that some species have been isolated only once during the season (Table 1). Strains of the same species isolated from a single plant but at different time points were regarded as independent strains, although possibly being identical. Apart from Fusarium species, Alternaria, Epicoccum, Mucor, and Trichoderma fungi were frequently occurring on asparagus plants tested (results not shown).

\section{Mycotoxins Analyzed in Asparagus Spears}

Different groups of mycotoxins were found in plant samples after tissue portions have been used for the isolation of Fusarium strains: fumonisins, moniliformin, beauvericin, and enniatins $\mathrm{A}, \mathrm{A}_{1}, \mathrm{~B}$, and $\mathrm{B}_{1}$ (Table 2). The highest concentrations of fumonisins were found in the spears collected in May, at the very beginning of the vegetation season. Later on, the amounts of mycotoxin accumulated dropped down substantially. Moreover, the differences were recorded in individual toxin concentrations for samples of the apical and basal stem parts. Interestingly, no uniform pattern could be observed, as some of the stems contained more mycotoxin in the apical part, while others in basal part of the stem (Table 2). The amounts of the HT-2 toxin measured for the spears with confirmed presence of $F$. sporotrichioides were below detection limits (data not shown).

\section{Mycotoxins Analyzed in Fungal Strain Cultures}

Furthermore, the amounts of mycotoxins synthesized by individual Fusarium strains were analyzed using sterile rice grain cultures. Moderate levels of toxins have been found for most of the $F$. proliferatum, $F$. equiseti, and $F$. sporotrichioides strains (Table 3). Four out of $12 \mathrm{~F}$. sporotrichioides strains (KF 3791, KF 3818, KF 3835, and KF 3840) did not synthesize the HT-2 toxin (group A trichothecene), and the ability to synthesize zearalenone was confirmed for all strains of $F$. equiseti and F. culmorum, the species known as casual producers of the respective mycotoxins (Table 3 ).

\section{Discussion}

The knowledge about the occurrence of Fusarium pathogens on various perennial plants in temperate climate (including cultivated and non-cultivated species) has been rather scarce. 
Fig. 2 Overall frequencies of eight Fusarium species (represented by 44 isolates in total) identified in nine asparagus plants collected at four time points (see Table 1 for details)

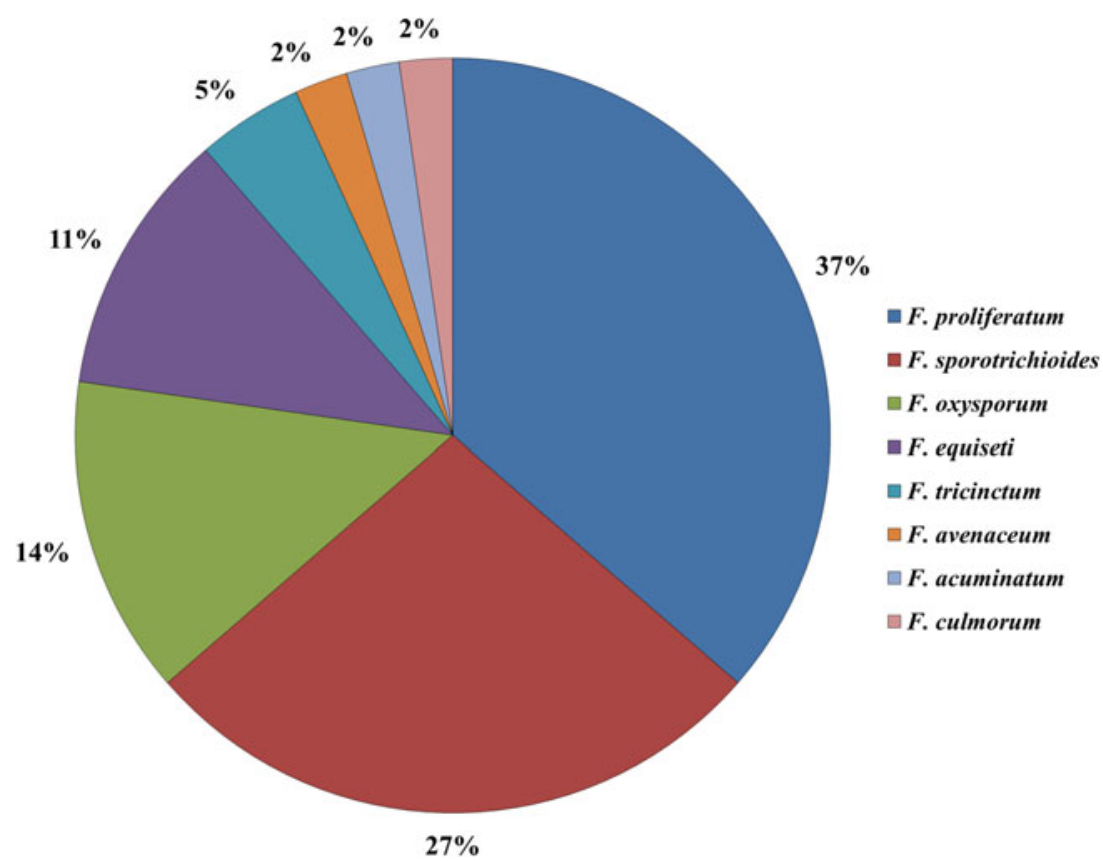

Some of the reports published were focused on tropical fruit crops, including banana, date palm, mango, and pineapple $[8$, $19,20,28,29]$ and ornamental plants [30]. A. officinalis L. is another perennial crop that can serve as a host to a range of fungal species, and the incidence and frequencies of individual Fusarium species on cultivated asparagus plants has been studied for many years $[6,7,18,31,32]$. F. oxysporum appeared as the most frequent pathogenic species causing crown rot and other Fusarium-related diseases in cultivated asparagus (Authors' studies, unpublished), along with $F$. proliferatum [5]. Consequently, a lot of researchers' attention was devoted to harmful mycotoxins synthesized by the fungi colonizing almost every plant tissue $[1,33]$. However, to control the fungal contaminations of a perennial species is often a difficult task, since the infection process runs symptomless in many cases, although the plant tissues are by then heavily overgrown with fungal hyphae and contaminated with mycotoxins [4, 7]. Moreover, other specific factors (harvest time and frequency) affect the symptom occurrence on asparagus plants [34]. The worldwide distribution of crops colonized with fungi can have significant impact on ambient pathogen populations and introduction of new species into the local environment [8]. On the other hand, not much data is available on the fungal community present in wildly growing crop plants, i.e., those that are not protected, fertilized, and regularly harvested. Since the environment of the plant is different comparing to the cultivated plants (the proximity of rural plant and animal communities instead of a monoculture), it is also likely that mycobiota associated with these asparagus plants change, becoming endophytes rather than pathogens to endure inside the plant for a longer period of time. Similar relationships have already been noticed for asparagus plantations [34]. Therefore, the basic scientific aim of the present study was to evaluate the diversity of Fusarium spp. colonizing wildly growing asparagus plants. Research done during recent years (2009-2012) has proven the F. oxysporum to be consistently the main pathogen isolated from cultivated asparagus spears, followed by $F$. proliferatum (unpublished data) and just a few additional species ( $F$. equiseti and $F$. avenaceum). The fact that the Fusarium community in wild plants is different from that of cultivated plants, may be as an outcome of the variation in environmental factors. Consequently, the secondary metabolites synthesized by the mycobiota have to be adjusted to such a specific lifestyle, or, alternatively, it can play different roles than just influencing the infection of the plant.

Nine plants were monitored for the presence of young spears in 1-month intervals. Additionally, green and ripe (red) fruit, as well as three crown samples, were screened for mycotoxin contamination and presence of Fusarium fungi. The species diversity found in non-cultivated asparagus plants was found to be higher than that reported for the marketable (i.e., cultivated) asparagus spears $[4,34]$. This finding might suggest that asparagus plants can likely be infected with numerous Fusarium species and agricultural techniques can possibly limit their number to just two or three observed with the highest frequencies: $F$. oxysporum and $F$. proliferatum $[5,18]$. Actually, the latter species was also present among the most frequently isolated fungi in the present study (Fig. 2 and Table 1). As a consequence, the contamination of plant tissues with fumonisins appears as very likely, since $F$. proliferatum often synthesizes FBs in infected plant tissues $[1,8,35,36]$. Among 
Table 2 Mean values ( \pm standard deviations) for mycotoxins in fresh asparagus plant tissues collected at four time points through May-October 2013 in Central Poland (in $\mathrm{ng} / \mathrm{g}$ )

Plant no. Plant part Mycotoxins (ng/g)

\begin{tabular}{|c|c|c|c|c|c|c|c|c|c|c|}
\hline & & & & & & & & & \\
\hline & & $\mathrm{FB}_{1}$ & $\mathrm{FB}_{2}$ & $\mathrm{FB}_{3}$ & Enn B & Enn $B_{1}$ & Enn $A_{1}$ & Enn A & MON & BEA \\
\hline \multicolumn{11}{|l|}{ May } \\
\hline 1 & Spear & $3.27 \pm 0.41$ & $0.34 \pm 0.04$ & $0.21 \pm 0.03$ & - & - & - & - & - & - \\
\hline \multirow[t]{3}{*}{2} & Top & $9.33 \pm 1.11$ & $1.05 \pm 0.13$ & nd & nd & nd & nd & nd & $10.45 \pm 1.27$ & $103.64 \pm 9.53$ \\
\hline & Base & $5.38 \pm 0.47$ & nd & nd & $20.16 \pm 3.08$ & nd & nd & nd & nd & $42.54 \pm 3.74$ \\
\hline & Spear & $9.29 \pm 0.85$ & $1.08 \pm 0.14$ & $0.76 \pm 0.08$ & - & - & - & - & - & - \\
\hline \multirow[t]{2}{*}{3} & Top & $6.51 \pm 0.72$ & $0.38 \pm 0.05$ & nd & nd & nd & $43.49 \pm 3.92$ & nd & nd & nd \\
\hline & Base & $5.21 \pm 0.49$ & nd & nd & nd & nd & nd & nd & nd & $47.57 \pm 4.25$ \\
\hline 4 & Spear & $2.25 \pm 0.18$ & $0.14 \pm 0.02$ & $0.06 \pm 0.01$ & - & - & - & - & - & - \\
\hline \multirow[t]{2}{*}{5} & Top & $2.83 \pm 0.33$ & nd & nd & nd & nd & nd & nd & $15.96 \pm 2.02$ & nd \\
\hline & Base & $4.02 \pm 0.35$ & nd & nd & $40.33 \pm 5.12$ & nd & nd & nd & nd & nd \\
\hline 6 & Spear & $19.52 \pm 2.02$ & $0.98 \pm 0.12$ & nd & - & - & - & - & - & - \\
\hline 8 & Spear & $2.87 \pm 0.37$ & nd & nd & nd & nd & nd & nd & nd & $24.77 \pm 3.18$ \\
\hline \multicolumn{11}{|c|}{ June } \\
\hline \multirow[t]{4}{*}{1} & Young spear & nd & nd & nd & - & - & - & - & - & - \\
\hline & Crown & nd & nd & nd & - & - & - & - & - & - \\
\hline & Green fruit & nd & nd & nd & - & - & - & - & - & - \\
\hline & Spear & $3.20 \pm 0.28$ & $2.07 \pm 0.25$ & nd & nd & nd & $23.35 \pm 2.05$ & nd & nd & $34.56 \pm 4.21$ \\
\hline \multirow[t]{3}{*}{2} & Young spear & $18.15 \pm 2.01$ & $0.17 \pm 0.02$ & nd & - & - & - & - & - & - \\
\hline & Crown & $14.82 \pm 1.55$ & $1.37 \pm 0.15$ & $0.96 \pm 0.11$ & - & - & - & - & - & - \\
\hline & Spear & $1.34 \pm 0.14$ & nd & nd & - & - & - & - & - & - \\
\hline \multirow[t]{3}{*}{3} & Young spear & $0.11 \pm 0.02$ & nd & nd & - & - & - & - & - & - \\
\hline & Crown & nd & nd & nd & - & - & - & - & - & - \\
\hline & Spear & nd & nd & nd & - & - & - & - & - & - \\
\hline 4 & Spear & $6.51 \pm 0.81$ & $0.46 \pm 0.06$ & nd & nd & nd & nd & nd & nd & nd \\
\hline 5 & Spear & $2.62 \pm 0.36$ & nd & nd & $54.73 \pm 4.87$ & nd & nd & nd & nd & $21.31 \pm 2.23$ \\
\hline 6 & Spear & nd & nd & nd & nd & nd & nd & nd & nd & nd \\
\hline 7 & Spear & nd & nd & nd & nd & nd & $23.22 \pm 3.16$ & nd & nd & $20.39 \pm 1.84$ \\
\hline \multirow[t]{5}{*}{9} & Spear & $4.14 \pm 0.34$ & $0.36 \pm 0.04$ & nd & nd & nd & $15.02 \pm 2.05$ & nd & nd & $23.64 \pm 2.25$ \\
\hline & Top & $7.23 \pm 0.86$ & nd & nd & - & - & - & - & - & - \\
\hline & Base & $14.21 \pm 1.77$ & $0.84 \pm 0.07$ & nd & - & - & - & - & - & - \\
\hline & Top & $9.36 \pm 1.15$ & $0.71 \pm 0.08$ & nd & - & - & - & - & - & - \\
\hline & Base & $13.66 \pm 1.40$ & $1.02 \pm 0.21$ & nd & - & - & - & - & - & - \\
\hline \multicolumn{11}{|l|}{ July } \\
\hline \multirow[t]{2}{*}{1} & Top & $0.79 \pm 0.11$ & nd & nd & - & - & - & - & - & - \\
\hline & Base & nd & nd & nd & - & - & - & - & - & - \\
\hline 4 & Red fruit & $27.37 \pm 3.02$ & $0.98 \pm 0.10$ & nd & - & - & - & - & - & - \\
\hline 6 & Spear & $5.00 \pm 0.54$ & nd & nd & - & - & - & - & - & - \\
\hline \multirow[t]{2}{*}{7} & Top & $132.99 \pm 15.83$ & $6.74 \pm 0.72$ & $5.13 \pm 0.55$ & - & - & - & - & - & - \\
\hline & Base & $26.09 \pm 2.92$ & $2.11 \pm 0.30$ & nd & - & - & - & - & - & - \\
\hline \multirow[t]{2}{*}{9} & Top & nd & nd & nd & - & - & - & - & - & - \\
\hline & Base & $0.21 \pm 0.01$ & nd & nd & - & - & - & - & - & - \\
\hline \multicolumn{11}{|c|}{ October } \\
\hline 1 & Spear & $31.82 \pm 3.66$ & $2.15 \pm 0.31$ & nd & nd & nd & $47.29 \pm 5.11$ & nd & nd & $10.74 \pm 0.98$ \\
\hline 2 & Spear & $5.55 \pm 0.67$ & nd & nd & nd & nd & $16.00 \pm 2.07$ & nd & nd & nd \\
\hline 3 & Spear & $6.86 \pm 0.75$ & nd & nd & - & - & - & - & - & - \\
\hline 4 & Spear & $1.07 \pm 0.25$ & nd & nd & nd & nd & nd & nd & $27.13 \pm 3.14$ & $27.10 \pm 3.15$ \\
\hline
\end{tabular}


Table 2 (continued)

\begin{tabular}{|c|c|c|c|c|c|c|c|c|c|c|}
\hline \multirow[t]{2}{*}{ Plant no. } & \multirow[t]{2}{*}{ Plant part } & \multicolumn{9}{|c|}{ Mycotoxins (ng/g) } \\
\hline & & $\mathrm{FB}_{1}$ & $\mathrm{FB}_{2}$ & $\mathrm{FB}_{3}$ & Enn B & Enn $B_{1}$ & Enn $A_{1}$ & Enn A & MON & BEA \\
\hline 5 & Spear & $1.11 \pm 0.17$ & nd & nd & - & - & - & - & - & - \\
\hline 6 & Spear & $13.50 \pm 1.48$ & $2.45 \pm 0.19$ & nd & - & - & - & - & - & - \\
\hline 7 & Spear & nd & nd & nd & - & - & - & - & - & - \\
\hline 8 & Spear & $80.23 \pm 8.11$ & $8.14 \pm 0.94$ & $1.16 \pm 0.13$ & - & - & - & - & - & - \\
\hline 9 & Spear & $12.79 \pm 1.45$ & $2.50 \pm 0.41$ & nd & nd & nd & nd & nd & $44.96 \pm 4.32$ & nd \\
\hline
\end{tabular}

FB amounts have been re-calculated for the fresh weight amounts. Please refer to Table 2 for spear availability $n d$ below detection limit

44 Fusarium isolates purified during the present study, while $F$. proliferatum and $F$. sporotrichioides were the prevailing species, only six $F$. oxysporum isolates were found (Table 1 and Fig. 2). Noteworthy, F. sporotrichioides was identified in asparagus plants with high frequency. To the best of our knowledge, it has not been reported as the pathogen of asparagus until now; therefore, more attention should be focused on cultivated plants to confirm its pathogenicity toward this crop. Thus, the identification of this species in wild asparagus appears as one of the most important findings of the present study, since the species is a well-known producer of the most toxic Fusarium metabolites, namely, the T-2 and HT-2 toxins [37] and the possible risk of contamination of asparagus spears with those compounds would pose a serious risk to the consumers. It is possible that weather conditions were favorable for $F$. sporotrichioides in this particular season, as it has also been frequently identified in tissues of other crop species, like Triticum durum (authors' data, unpublished). Nevertheless, the species was identified in 2014 season in wild asparagus plants collected from other localities of Poland (data not shown); therefore, it should be considered as at least associated with this crop.

The diversity of Fusarium species in field-grown asparagus plants was usually limited to few species [1, 5-7, 31, 32]. Concerning individual plants, the incidence of Fusarium species varied significantly during the season, while from the plants \#8 and \#9, only $F$. proliferatum was isolated, and from plants \#2 and \#5, five and four different species were derived in total, respectively (Table 1). It seems that the incidence and prevalence of individual Fusarium species in the overall population are not constant and may change rapidly and continuously. On the other hand, fungi living as endophytes can be found in the same plants throughout the season. All species but one were isolated at the beginning of the season (May), while at the end (October), only few were isolated (Table 1). Definitely, additional research using dedicated approaches is needed to reveal the factors influencing those changes.

Fumonisins, associated with $F$. proliferatum as the main producer, have been the first mycotoxins of concern for many years, when asparagus plants were analyzed. Also in the present study, fumonisins $B_{1}-B_{3}$ were the most abundant mycotoxins found in virtually all plant samples. Moniliformin and cyclic peptide toxins (beauvericin and enniatins) were quantified at lower concentrations and frequencies (Table 2). Although mycotoxins were present in asparagus plants throughout the whole season, the highest levels of toxins were measured at the beginning of vegetation season (samples collected in May), particularly for the plants \#1 and \#2. Contradictory, the crowns of plants \#1 and \#3 contained no detectable FBs, despite the mycotoxins were present in the spears of the respective plants (Table 2). The presence of the fungus does not necessary mean the mycotoxin contamination. Moreover, in some plants sampled in October, there were fumonisins present, although no fungal strain has been isolated at that time (Tables 1 and 2). The absence of fungal strains late in the season is not surprising as the metabolic activity of most organisms is much lower than in the Spring (May). Thus, the latest spears may be sometimes not colonized by fungus, although the toxin may be spread along the vascular system.

Noteworthy, more toxins were usually present in the apical parts of the spear, than in the basal parts (Table 2), which could be likely explained by more intensive growth of the fungus in rapidly proliferating tissues. To confirm this hypothesis, however, additional experiments should be performed, measuring quantitatively fungal biomass in plant tissues (e.g., by ergosterol contents analysis or qPCR analyses). The level of mycotoxin synthesized by the pathogen highly depends on metabolic activity of the fungus, which in turn is related to a number of environmental factors (like photoperiod and temperature). These factors may be responsible for high FB amounts at the beginning of growing season (May). Subsequent decrease in the samples of respective plants is probably the result of lower activity of the pathogen than in the Spring. Few measured concentrations of FBs found in plant samples (Table 2) were higher than these reported for cultivated plants $[4,18]$. Analyses of crown mycotoxin contamination late in the season could give more details about seasonal fluctuations in mycotoxin contents in asparagus plants. 


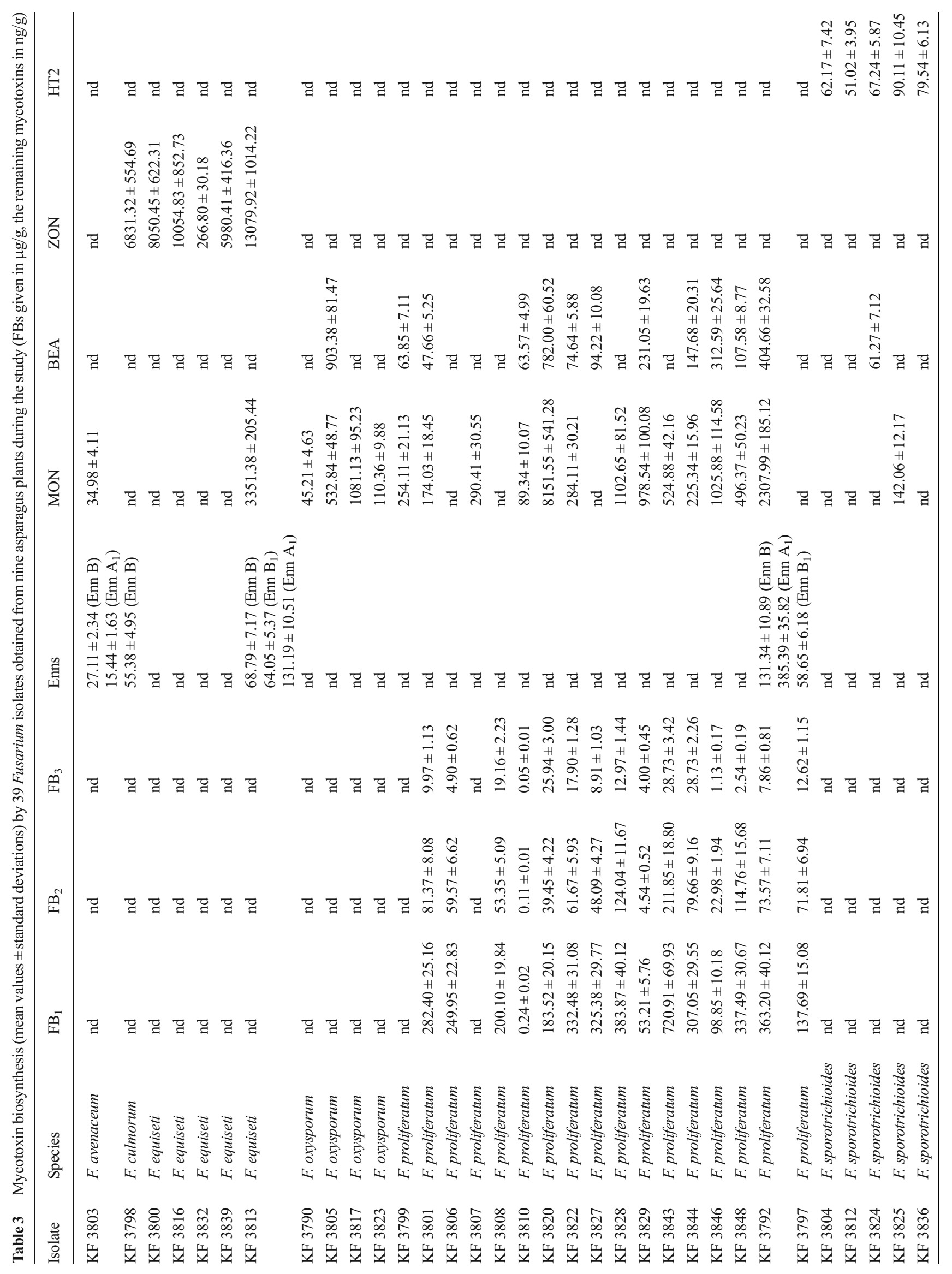




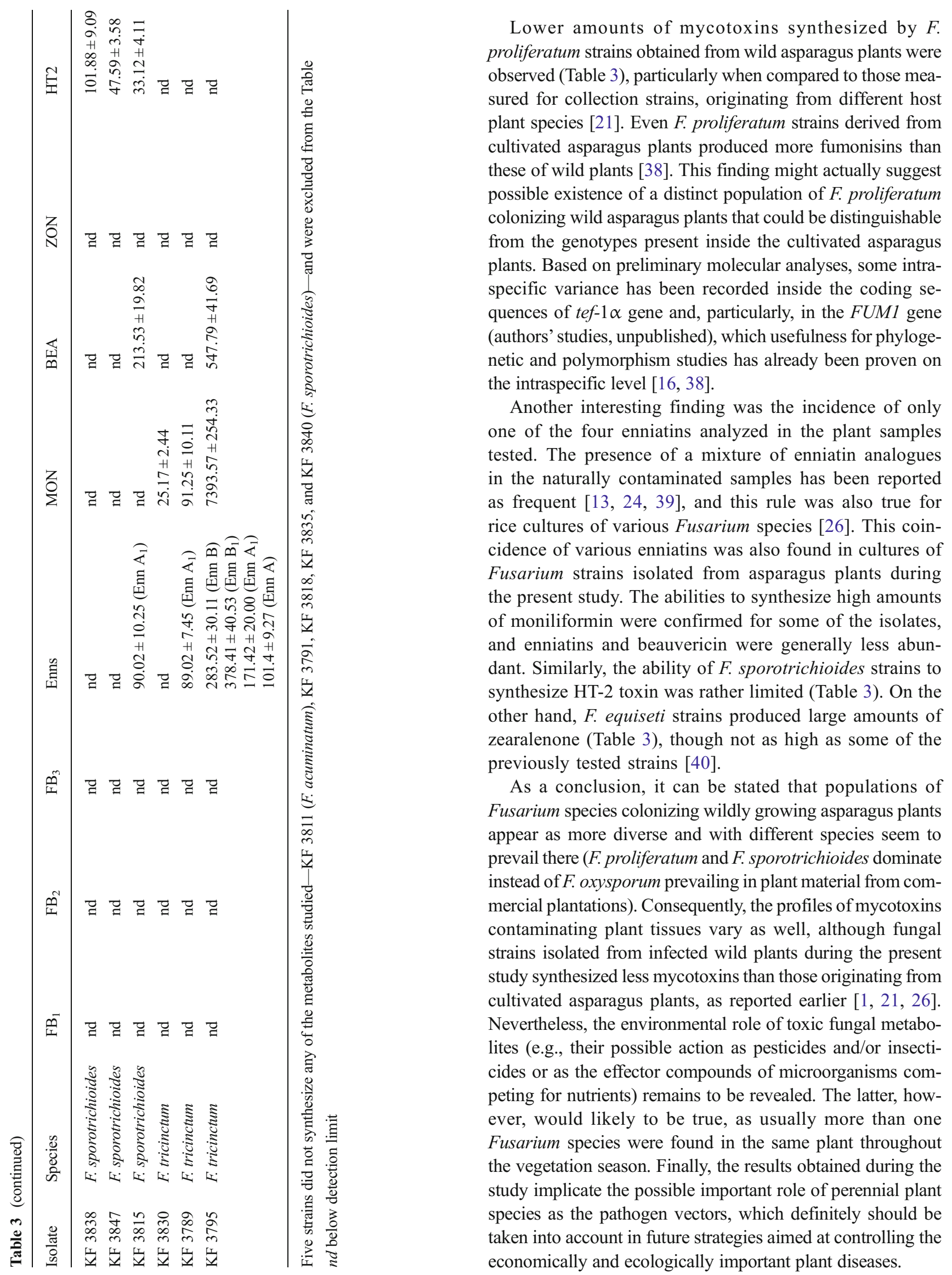




\section{Compliance with Ethical Standards}

Conflict of Interest The authors declare no conflict of interest.

Open Access This article is distributed under the terms of the Creative Commons Attribution 4.0 International License (http:// creativecommons.org/licenses/by/4.0/), which permits unrestricted use, distribution, and reproduction in any medium, provided you give appropriate credit to the original author(s) and the source, provide a link to the Creative Commons license, and indicate if changes were made.

\section{References}

1. von Bargen S, Martinez O, Schadock I, Eisold A-M, Gossmann M, Buttner C (2009) Genetic variability of phytopathogenic Fusarium proliferatum associated with crown rot in Asparagus officinalis. $\mathrm{J}$ Phytopathol 157:446-456

2. Luce A, Mattas K, Tzouramani I, Paroussi G, Tsakiridou E, Raptou E (2006) Financial assessment of a new soil heating technology for off-season Asparagus production. Am J Agric Biol Sci 1:6-9

3. Logrieco A, Bottalico A, Mulè G, Moretti A, Perrone G (2003) Epidemiology of toxigenic fungi and their associated mycotoxins for some Mediterranean crops. Eur J Plant Pathol 109:645-667

4. Karolewski Z, Waśkiewicz A, Irzykowska L, Bocianowski J, Kostecki M, Goliński P, Knaflewski M, Weber Z (2011) Fungi presence and their mycotoxins distribution in asparagus spears. Pol J Environ Stud 20:911-919

5. Weber Z, Kostecki M, von Bargen S, Gossmann M, Waśkiewicz A, Bocianowski J, Knaflewski M, Büttner C, Goliński P (2006) Fusarium species colonizing spears and forming mycotoxins in field samples of asparagus from Germany and Poland. J Phytopathol 154:209-216

6. Vujanovic V, Hamel C, Yergeau E, St-Arnaud M (2006) Biodiversity and biogeography of Fusarium species from northeastern North American asparagus fields based on microbiological and molecular approaches. Microb Ecol 51:242-255

7. Wang J, Wang X, Zhou Y, Du L, Wang Q (2010) Fumonisin detection and analysis of potential fumonisin-producing Fusarium spp. in asparagus (Asparagus officinalis L.) in Zhejiang Province of China. J Sci Food Agric 90:836-842

8. Stępień $€$, Koczyk G, Waśkiewicz A (2013) Diversity of Fusarium species and mycotoxins contaminating pineapple. J Appl Genet 54: 367-380

9. Logrieco A, Visconti A (2004) An overview on toxigenic fungi and mycotoxins in Europe. Kluwer Academic Publishers, DordrechtDresden-London, $\mathrm{p} 252$

10. Desjardins AE (2006) Fusarium, mycotoxins, chemistry, Genet Biol APS, St Paul, USA, pp. 259

11. Stepień $€$, Waśkiewicz A, Wilman K (2015) Host extract modulates metabolism and fumonisin biosynthesis by the plant-pathogenic fungus Fusarium proliferatum. Int J Food Microbiol 193:74-81

12. Waśkiewicz A, Stępień $€$, Wilman K, Kachlicki P (2013) Diversity of pea-associated $F$. proliferatum and $F$. verticillioides populations revealed by FUM1 sequence analysis and fumonisin biosynthesis. Toxins 5:488-503

13. Chełkowski J, Ritieni A, Wiśniewska H, Mulè G, Logrieco A (2007) Occurrence of toxic hexadepsipeptides in preharvest maize ear rot infected by Fusarium poae in Poland. J Phytopathol 155:8-12

14. Stępień $Ł$, Gromadzka K, Chełkowski J (2012) Polymorphism of mycotoxin biosynthetic genes among Fusarium equiseti isolates from Italy and Poland. J Appl Genet 53:227-236
15. Wiśniewska H, Stępień $€$, Waśkiewicz A, Beszterda M, Góral T, Belter J (2014) Toxigenic Fusarium species infecting wheat heads in Poland. Cent Eur J Biol 9:163-172

16. Stępien $€$ (2014) The use of Fusarium secondary metabolite biosynthetic genes in chemotypic and phylogenetic studies. Crit Rev Microbiol 40:176-185

17. Thrane U, Adler A, Clasen PE, Galvano F, Langseth W, Lew H, Logrieco A, Nielsen KF, Ritieni A (2004) Diversity in metabolite production by Fusarium langsethiae, Fusarium poae, and Fusarium sporotrichioides. Int J Food Microbiol 95:257-266

18. Logrieco A, Doko B, Moretti A, Frisullo S, Visconti A (1998) Occurrence of fumonisin $\mathrm{B}_{1}$ and $\mathrm{B}_{2}$ in Fusarium proliferatum infected asparagus plants. J Agric Food Chem 46:5201-5204

19. van Hove F, Waalwijk C, Logrieco A, Munaut F, Moretti A (2011) Gibberella musae (Fusarium musae) sp. nov., a recently discovered species from banana is sister to $F$. verticillioides. Mycologia 103: 570-585

20. Ploetz RC (2006) Fusarium-induced diseases of tropical, perennial crops. Phytopathology 96:648-652

21. Waśkiewicz A, Stępień $Ł$ (2012) Mycotoxins biosynthesized by plant-derived Fusarium isolates. Arh Hig Rada Toksikol 63:479488

22. Rodriguez-Estrada AE, Jonkers W, Kistler HC, May G (2012) Interactions between Fusarium verticillioides, Ustilago maydis, and Zea mays: an endophyte, a pathogen, and their shared plant host. Fungal Genet Biol 49:578-587

23. Leslie JF, Summerell BA (2006) The Fusarium laboratory manual. Blackwell Publishing, Iowa, pp 1-388

24. Stępień $Ł$, Jestoi M, Chełkowski J (2013) Cyclic hexadepsipeptides in wheat field samples and esynl gene divergence among enniatin producing Fusarium avenaceum strains. World Mycotoxin J 6:399409

25. Stępień $Ł$, Chełkowski J, Wenzel G, Mohler V (2004) Combined use of linked markers for genotyping the $\mathrm{Pm} 1$ locus in common wheat. Cell Mol Biol Lett 9(4B):819-827

26. Stępień $€$, Waśkiewicz A (2013) Sequence divergence of the enniatin synthase gene in relation to production of beauvericin and enniatins in Fusarium species. Toxins 5:537-555

27. Visconti A, Lattanzio VM, Pascale M, Haidukowski M (2005) Analysis of T-2 and HT-2 toxins in cereal grains by immunoaffinity clean-up and liquid chromatography with fluorescence detection. J Chromatogr A 1075:151-158

28. Kerényi Z, Mulè G, Moretti A, Waalwjik C, Hornok L (2002) Fertility and mating type assessment within Fusarium proliferatum isolates from different host plants. J Appl Genet 43:55-68

29. Mohamed Nor NMI, Salleh B, Leslie JF (2013) Fusarium species associated with mango malformation in Peninsular Malaysia. J Phytopathol 161:617-624

30. Zhang J, Wu X, Bi Y, Wu Y, Iin G, He Y, Mao Z (2013) First report of Fusarium proliferatum infecting carnation Dianthus caryophyllus L. in China. J Phytopathol 161:850-854

31. Borrego-Benjumea A, Basallote-Ureba MJ, Melero-Vara JM, Abbasi PA (2014) Characterization of Fusarium isolates from asparagus fields in southwestern Ontario and influence of soil organic amendments on Fusarium crown and root rot. Phytopathology 104:403-415

32. Seefelder W, Gossmann M, Humpf HU (2002) Analysis of fumonisin $\mathrm{B}(1)$ in Fusarium proliferatum-infected asparagus spears and garlic bulbs from Germany by liquid chromatographyelectrospray ionization mass spectrometry. J Agric Food Chem 50: 2778-2781

33. Waśkiewicz A, Irzykowska L, Drzewiecka K, Bocianowski J, Dobosz B, Weber Z, Karolewski Z, Krzyminiewski R, Goliński P (2013) Plant-pathogen interactions during infection process of asparagus with Fusarium spp. Cent Eur J Biol 8: $1065-1076$ 
34. Yergeau E, Sommerville DW, Maheux E, Vujanovic V, Hamel C, Whalen JK, St-Arnaud M (2006) Relationships between Fusarium population structure, soil nutrient status and disease incidence in field-grown asparagus. FEMS Microbiol Ecol 58:394-403

35. Jurado M, Marín P, Callejas C, Moretti A, Vázquez C, GonzálezJaén MT (2010) Genetic variability and fumonisin production by Fusarium proliferatum. Food Microbiol 27:50-57

36. Wilman K, Stępień Ł, Fabiańska I, Kachlicki P (2014) Plantpathogenic fungi present on seeds of different pea cultivars in Poland. Arch Ind Hyg Toxicol 65:329-337

37. Mirocha CJ, Abbas HK, Kommedahl T, Jarvis BB (1989) Mycotoxin production by Fusarium oxysporum and Fusarium sporotrichioides isolated from Baccharis spp. from Brazil. Appl Environ Microbiol 55:254-255

38. Stępień $€$, Koczyk G, Waśkiewicz A (2011) Genetic and phenotypic variation of Fusarium proliferatum isolates from different host species. J Appl Genet 52:487-496

39. Jestoi M (2008) Emerging Fusarium mycotoxins: fusaproliferin, beauvericin, enniatins, and moniliformin - a review. Crit Rev Food Sci Nutr 48:21-49

40. Chełkowski J, Gromadzka K, Stępień Ł, Lenc L, Kostecki M, Berthiller F (2012) Fusarium species, zearalenone and deoxynivalenol content in preharvest scabby wheat heads from Poland. World Mycotoxin J 5:133-141 